ESJ Social Sciences

\title{
COVID-19 Pandemic Social Media and Stress
}

\author{
Md. Atiqur Rahman, MSS
}

Dept. of Mass Communication \& Journalism

University of Rajshahi, Bangladesh

Md. Ashraful Islam, M.Sc

Dept. of Information \& Communication Engineering

University of Rajshahi, Bangladesh

Doi:10.19044/esj.2021.v17n35p166

Submitted: 30 August 2021

Accepted: 20 October 2021

Published: 31 October 2021
Copyright 2021 Author(s)

Under Creative Commons BY-NC-ND

4.0 OPEN ACCESS

Cite As:

Rahman M.A. \& Islam M.A. (2021). COVID-19 Pandemic Social Media and Stress. European Scientific Journal, ESJ, 17 (35), 166. https://doi.org/10.19044/esj.2021.v17n35p166

\begin{abstract}
Last few years, SARS-coronavirus 2 is sweeping the globe and millions of people are being infected and died. In this situation, citizens and health-care workers would be put in danger if there is a lack of consciousness, knowledge and preparation during this crisis. At the same time, a vast amount of potentially damaging misinformation is spreading at a faster rate than the virus itself. The most of these false rumours are spread via social media. This paper focuses on the COVID-19 linked huge rumour, stigma and conspiracy theories disseminating on the social media during pandemic in Bangladesh perspective. An internet-based interview and primary data was quantitatively analyzed for survey of this paper. The findings demonstrate that social media plays a crucial role in the diffusion of information about the COVID-19 outbreak in Bangladesh, including bewilderment, anxiety and panic. This study also revealed that Bangladeshi youth society has the higher levels of stress especially among those who followed the news of pandemic in social networks compared to the rest of the population. Another noteworthy finding is that social media was particularly helpful in reducing anxiety and alienation by allowing the general people to stay in touch with friends, family and others via audio-visual group chat. Different aspects of social networking sites use are also described.
\end{abstract}

Keywords: COVID-19, infodemic, panic, social media 


\section{Introduction}

Recently world pandemic of COVID-19 has not only created major problems for health systems around the world, but has also sparked the emergence of various rumors, hoaxes and misinformation about the etiology, outcomes, disease prevention and cure. This propagation of misinformation masks safe-healthy practices and promotes negligence that amplifies the transmission of the infection and eventually results in poor physical and mental health outcomes among individual people. COVID-19 has been recognized as one of the most serious dangers to public health by the World Health Organization, and the public's response has been influenced like never before by a worldwide infodemic (or misinfodemic) [Banerjee et al, 2021]. COVID-19 infectious illness initially appeared in late December 2019 in Wuhan, China and has since spread to nearly every country on the planet, became a pandemic. Several websites have released information on COVID19 and offered varied suggestions to its users and residents in order to escape this virus. Social media has become a source of transmitting information to the public. On COVID-19, articles from online newspapers are linked on social media sites like Facebook, WhatsApp, Twitter, Instragram, and Telegram, among others, letting stories to easily become viral. [Onwe et al, 2020].

The majority of the COVID-19 related material is disseminated through social networking sites, particularly Facebook. Statistics shows that about 361,000,000 videos were posted with the COVID-19 categorization on YouTube in April, 2020 and more than 2.9 billion users on cell phones using social media daily [www.statista.com]. False news propagates on social media more quickly than news from trustworthy outlets, destroying the balance of reliability of the news ecosystem. This sort of dissemination of misinformation can cause mass anxiety and adversely affect the health of individuals. In addition, false information and rumours about COVID-19 obstruct the practice of safe behaviors [hand sanitizing - social distancing] and encourage incorrect activities that increase the spread of the virus and eventually lead to poor results in physical and mental health. During the lockdown, Bangladeshis depended heavily on internet-based social media to keep up with infectionrelated information, prevention measures, and medication of the Covid-19 epidemic, while healthcare facilities were inadequate in terms of infection frequencies and death tolls [Islam, 2021].

Within weeks of the outbreak of COVID-19 in China, the world was circulating with false rumours and conspiracy theories about COVID-19. This social media spread this to the rest of the planet, traveled faster than the COVID-19 propagated in Bangladesh also. The common public appears to embrace rumors and spreads them on social media platforms, resulting in misinformation going viral and creating chaos [Shahid et al, 2020]. Indeed, 
there are numerous fake stories, deliberate misinformation, and unfounded conspiracy theories about COVID-19 in both online and offline. [Gundaz, 2020]. UN Secretary-General Mr. Antonio Guterres launched a plan to fill the internet with evidence and science to combat the "poison" of misinformation that's also endangering more lives. He claimed that a worldwide "misinfodemic" about the novel coronavirus was circulating "harmful health advice and snake-oil solutions" [www.thestatesman.com]. Dr. Tedros, Director General of the World Health Organization [WHO] called this the battle against "trolls and conspiracy theories" [www.bbc.com].

This "mis-infodemic" regarding the novel coronavirus via social media has led some crucial research study. In the research paper [Islam et al., 2020], [Tasnim et al., 2020; www.tandfonline.com] show that misinformation may have major consequences for individuals and communities if rumours, stigma and conspiracy theories are prioritized above evidence-based policies. In [www.ncbi.nlm.nih.gov] study revealed that social media has led in the spread of anxiety about the COVID-19 outbreak. Many individuals increasingly seek information on online that they considered to be useful, leading to a wide variety of fake news consumption and dissemination, [Khalifa et al., 2021; Apuke, et al., 2020].

Therefore, we want to identify and examine the role of social media platforms in disseminating information about the COVID-19 outbreak especially in Bangladesh along with the following point.

To ascertain if the social media has aided rumour mongering about the pandemic.

Is there any role of social media to change healthy habits like hand washing and social distancing etc. in this pandemic?

What psychological effect did the news of multiple rumours, stigma and conspiracy theories have on consumers of social media networks? Whether the perceived pressure was higher among those who regularly followed the news of COVID-19 in social networks or the people who never followed this news in social media. To determine if social media's reputation has been harmed.

\section{Methodology}

The most popular and used social media in Bangladesh is Facebook which have $64.04 \%$ of total users [Apuke et al., 2020]. Therefore, the authors decided to study this platform along with Messenger and WhatsApp, which are the next most popular social networking site after facebook. This paper tracked rumours, stigma and conspiracy theories which were circulated via these social apps among the general population since the start of the COVID19 pandemic. Social media users have been playing a part in all stages of information diffusion since the start of the COVID-19 pandemic, including 
COVID-19 incidence and death, therapies, govt. initiatives etc. So, COVID19 related all the potential rumour, stigma and conspiracy theory were collected between June 01, 2020, and January 5, 2021, then reviewed and analyzed it. The authors gathered even more information, when the first COVID-19 patient was diagnosed in Bangladesh on March 8, 2020, and during the first lockdown. An internet-based open-ended questionnaire was designed for in-depth interviews. Participants were instantly asked a few questions outside of the questionnaire to obtain a thorough picture of the issue. Interviews were performed with 125 social media users who were between 15 to 58 years of age. Students, teachers, businesspeople, homemakers, laborers, politicians and other professions were among the participants. Authors then adopted a descriptive content analysis approach and presented a comparison.

\section{Social Media}

People's interactions with one another have evolved as a result of social media. Due to the evaluation of mobile communication, we are badly dependent on it. Recently we communicated with each other through social media. The development of communication includes, WiMAX [Islam et al., 2009; Islam et al, 2012; Awon et al., 2012; Halim et al., 2012; Islam et al, 2014; Tai et al., 2016; Roy et al., 2019], LTE [Islam et al., 2014], enable us to communicate with real feelings. Our previous research [Rahman et al, 2020] shows the impact of the evaluation of mobile communication on human health. Following that, social networking evolved to include the use of a profile to include information about a person and his or her preferences, as well as the integration of email. Latest update of social networking entails posting images, videos and stories as well as communicating with others through applications and messaging. All revolutionary technologies have their pros and cons. Social networking sites are no exception.

\section{Positive effects of social media}

Social networking sites are being used not only to connect and stay in touch with friends but also meet new people. Individuals may use these platforms to identify people with common and homogenous interests with which they can communicate and become acquainted. By using resources such as blogging and texting to share ideas and stories, social networking encourages creative expression [socialnetworking.procon.org] and enhances the influence and awareness of world events. Poems, music, pictures, TV shows, hobbies and several other items are shared by users.

Students' technical capabilities grow as a result of their use of social media, as well as their exposure to a variety of viewpoints. It has also aided communication skills and allowed people from all around the world to learn about different cultures. Students also use social media to discuss homework 
issues with their friends and to get assistance with projects [Reid, 2009]. It also enhances businesses as well. The Gezi Park Protests, the Arab Spring, the coup attempt on July 15th, and campaigns such as Greenpeace and Change.org are just a few examples of social movements where social media has played a crucial part in planning, organizing, and campaigning. [Aykurt et al, 2017]. The way people communicate in the world has already been drastically transformed by social networking.

\section{Negative effects of social media}

In order to correct the negative issues, the sites are constantly progressing and improving. One such scenario is using cell phones to enter social networking websites so that users can surf the internet on the move rather than stuck at a desk. Social media networks are a strong substitute of face-to-face social interaction, which is thought to result in decreased relations with others.

Online social networking is often a huge waste of time and is vulnerable to social alienation that can also lead to loneliness and reduced social skills [Mikami et al., 2010]. Crimes, cyber bullying is being taken place as well.

It has been found that mobile phones release electromagnetic radiation which is ingested by human brain and body. This ingestion disrupts memory and learning sites in the brain and can cause confusion and memory loss [Thomas, 2004]. It is also stated that electromagnetic exposure from cell phones can lead to cancer.

Although social networking sites might waste time, it could impact the environment in a state emergency or health emergency period like COVID-19 pandemic by helping people to connect and stay in contact with important information in this easy and convenient way.

\section{Information-Misinformation in Social-media in Bangladesh During Covid-19 Pandemic}

Several social media sites such as Facebook, Messenger, WhatsApp and YouTube have been used to construct a state of fear, apprehension, confusion and insecurity. Before anyone gets a chance to repair it; wrong, unreliable or misleading medical advice may circulate across the world with fake news and the spread of misinformation being the defining issues [www.weforum.org]. We are currently facing a public understanding epidemic with social media powerhouses like Facebook, Messenger, WhatsApp at the forefront.

We found 316 reports relevant to COVID-19 infodemic. Among those $85.76 \%$ records were rumor, $4.11 \%$ were stigma, $7.29 \%$ were hypotheses of conspiracy [conspiracy theory] and $2.85 \%$ were unspecified [others]. We 
examined two distinct phases of Information-misinformation. As we got, the first phase or wave of Information-misinformation was from March 2020 to May 2020. Second phase was from May to 2020 to January 2021.The first phase of infomedics was wide and strong and the second was relatively limited and weak. Fig. 1 shows the proportion of rumour, stigma and conspiracy theories. Rumours in the blue coloured which are $85.76 \%, 7.29 \%$ are conspiracy theory in orange coloured, stigma in gray coloured of $4.11 \%$ and others or unspecified of $2.85 \%$ are in yellow coloured.

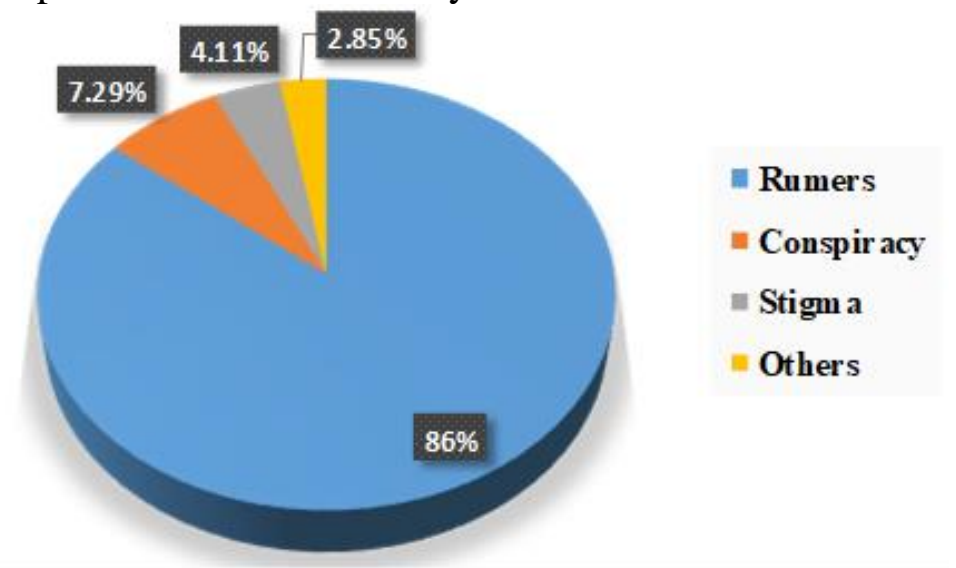

Fig. 1: Proportion of rumours, stigma and conspiracy theory during COVID-19

\section{Rumour}

Rumour was characterized as any unverified and compositionally significant arguments, remarks or discourse circulating on online forums about COVID-19. It was always the most widespread and dominant of all the types of information-misinformation we monitored. The number of rumors began to rise in February, 2020 and escalated until the end of the assessment, reaching its peak in 12-18 March, 2020. The majority of the rumors were linked to COVID-19 outbreak, fever, sickness, virus transmission, deaths as well as infection control techniques. Drinking ginger tea, keeping the throat moist, avoiding spicy foods, and the effects of vitamin C, D and zinc tablet supplementation to boost up immune system to reduce infection have also been noted. There were some rumours also we observed about consuming bleach or alcohol for protection and remedies from COVID-19 in addition to diet and vitamins to improve immunity, and a common circulating belief about how to self-diagnose coronavirus infection [Landsverk, 2020].

Fig. 2 shows six separate blue columns indicating the category of text and its proportion on social media during COVID-19, where $26 \%$ is about sickness, $19 \%$ is about the control of disease and its transmission, $21 \%$ is about treatment and prevention of illness, the reason of disease is $13 \%$, violence $2 \%$ and miscellaneous is $26 \%$. 


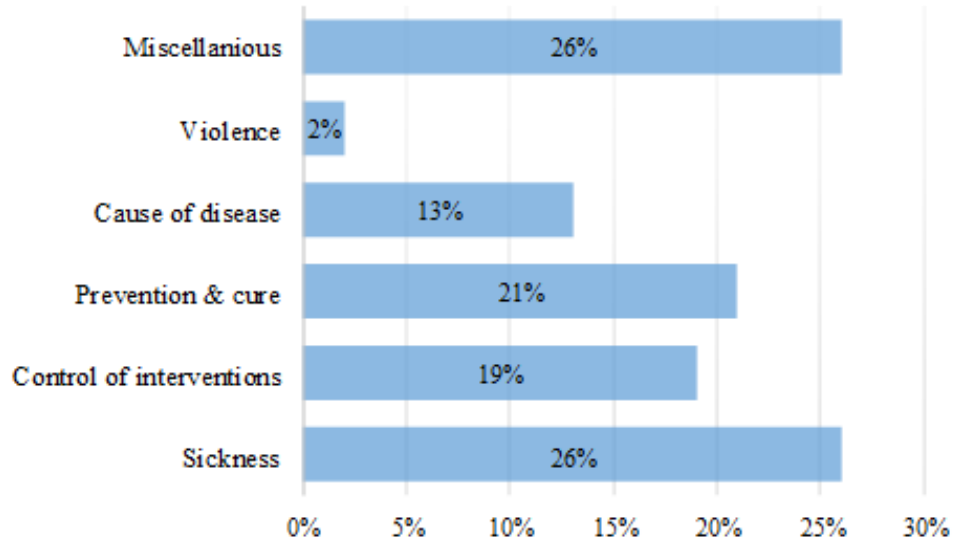

Fig. 2: Category of content of COVID-19 related information flowing in social media

\section{Stigma and discrimination}

Stigma has primarily been established as a socially developed phenomenon in which a person is specifically or implicitly marked by exposure, disease, travel background and ethnic origin, resulting in negative attitudes and stigma.

Individuals, including health workers have been threatened or physically assaulted or discriminated against by their landlords and neighbors in Bangladesh. In certain places, locals have closed roads and streets to keep outsiders away. Because of the hostility from the own building's neighbours, a medical healthcare professional was unable to enter his apartment of that building in capital town of Bangladesh. A doctor couple went on holiday to the village house after treatment of the corona patients but were not allowed to stay at home there. The villagers had built a room for them away from home to live there.

\section{The conspiracy theory}

Different theories connected to Covid-19 origins and harmful objectives are asserted, argued, and discussed. In Bangladesh, a number of conspiracy theories about the COVID-19 outbreak were floating online. COVID-19 was just a bio-weapon, according to one theory, which was manufactured by foreign intelligence services. Another hypothesis is that the lethal coronavirus was created and spread in China by a number of countries as part of a financial and psychological war targeting China. But at the other end, public believed that the virus was produced in a lab as part of a Chinese bio-warfare project, but it was designed as a weapon by the scientists from China. Concerning the existence of a COVID-19 vaccine or medicine, conspiracy theories have also appeared. According to one early theory, a vaccination for this virus has already been created, but the pandemic is only a pretext for further sales. 


\section{Discussion}

According to the participants in this report, social media has a significant influence on the dissemination of confusion, fear and panic linked with the COVID-19 epidemic in Bangladesh, with a potential detrimental impact on people's mental health and psychological well-being. To spread fear about the COVID-19 outbreak in Bangladesh, Facebook was still the most used social media platform. We found a co-relation between self-reported use of social media and the spread of COVID-19-related panic.

China, India, the United States, Spain, Brazil and Indonesia are responsible mostly where almost all of these rumors, stigma and conspiracy theories were originated and came in Bangladesh later. In the figure 3, 77.89\% of the reports which were incorrect, correct were $13.26 \%$, misguiding reports were $7.14 \%$ and $1.71 \%$ reports which were not confirmed about their authenticity are shown in blue columns.

It appears to have had more psychological impact, especially on the younger generation, as respondents aged 18 to 35 years were affected. Users are much more likely to get their information from social media than anybody else. People are also unwilling to distinguish between real and fake information on social media, leading to increased panic and speculations about the true nature of the pandemic. So this mental stress was higher among those who followed the news of pandemic in social networks compared to others in the society. This paper found a connection between higher social network participation and the prevalence of mental health issues like depression and anxiety.

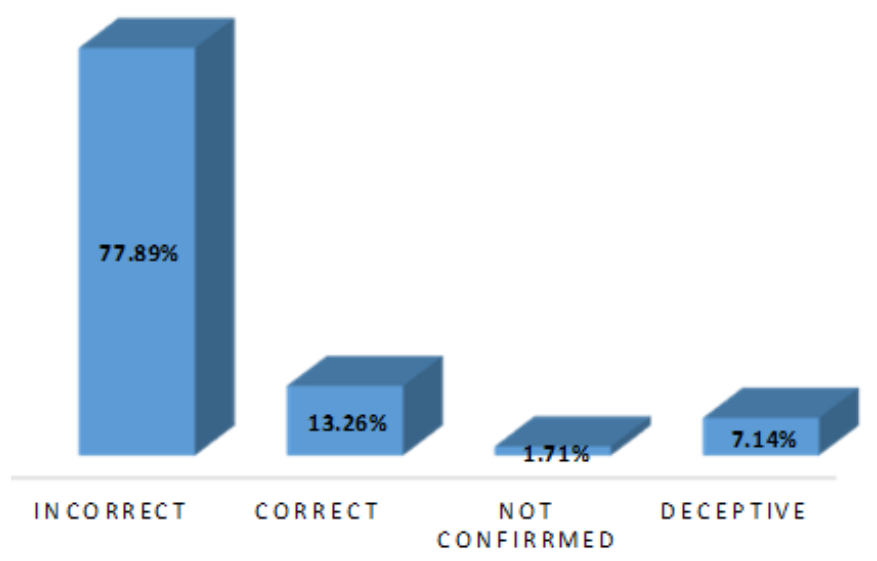

Fig. 3: Accuracy of information disseminated through social media about COVID-19

Finally, if rumours, stigma and conspiracy theories are prioritized above scientific guidelines, speculation may have serious consequences for public health. To create accurate risk awareness messages and strategy, government and concerned institutions must take into account the 
phenomenon of COVID-19 induced rumors, stigma and conspiracy theories circulated around Bangladesh. However, if used wisely and prudently, social media serves as a powerful tool for changing people's behavior and to promote the well-being of individual and public health.

\section{Steps Taken by the Authorities to Prevent Confusion Through Misinformation}

Since mid-March 2020, at least twelve citizens, such as a doctor, a prominent photographer, opposition leaders and academics have been detained for their remarks on coronavirus. The majority of them under the repressive "Digital Security Act 2018". The Ministry of Information has ordered the formation of a team to monitor social media and a variety of television stations for "rumours" about COVID-19 activities. Two government college professors were reportedly suspended for discussing the virus on social media. According to reports, one researcher was being investigated for publishing a paper that projected the effect of COVID-19.

The Ministry of Education temporarily suspended two government college teachers for uploading "provocative" comments and photos on Facebook on 25th March 2020. The teachers were being suspended for misconduct underneath the Government Servants Rules (Discipline and Appeal, 2018) for participating in practices "against government management, indiscipline, and against the public interest," according to the government order.

On 25th March 2020, the Bangladesh government released a circular designating 15 officials to track each TV station for "rumours" and "propaganda" about COVID-19. The order was revoked the following day and it became in an expanded form to include not only private news stations but also other media, including social media, which the officials would have to control [www.hrw.org].

\section{Recommendation}

In the critical moment of Covid-19 Pandemic, the situation became more murky due to social media. The government has taken some steps. But the necessary awareness, caution is required while receiving and sharing or disseminating information. It is important to use each piece of information only after verifying its accuracy. Otherwise, the government alone will not be able to control it completely by using force. And creating awareness is more effective than law enforcement in preventing infodemic. At this point, individuals, organizations and governments need to be more responsible in the long run. 


\section{Conclusion}

As in other parts of the world, there has been widespread rumor, stigma and conspiracy theory in Bangladesh over the COVID-19 virus and its prevention, and people have embraced it. As a result, rather than raising consciousness about disease control, social media has spread fear, placing a strain as burden on a large portion of society. On the other end, social networking sites have proved to be extremely useful for the general public in keeping in touch audio-visually with friends and family during lockdown, quarantine or loneliness for a prolonged period of time, which has given temporary relief from anxiety, frustration. We now want to know if social media customers have daily concerns and anxieties, or if it has escalated since COVID-19. If it happens specially in pandemic then which reasons were behind these anxiety and it's nature.

\section{References:}

1. Banerjee, Debanjan, Meena, k.S. [2021], "COVID-19 as an "Infomedic" in Public Health: Critical Role of the Social Media", Front. Public Health,18 March, 2021, doi.org/10.3389/fpubh.2021.610623

2. Onwe, Emmanuel Chike, Chukwu, Joseph, Nwamini, Samuel Chukwuemeka, Nwankwo, Simon Ugochukwu, Elem, Stephen, Ogbaeja, Nelson Iroabuchi, Nwasum,Chinedu Jude, Nwakpu, Ekwutosi Sanita, Ogbodo, Jude Nwakpoke [2020]. "Analysis of Online Newspaers' Framing Patterns of COVID-19 in Nigeria." European Scientific Journal [ESJ], Vol.16, No.22, doi:10.19044/esj.2020.Vol.16, No.22, p. 217

3. Islam, Md. Monirul, Islam, Md. Mazharul, Ahmed, Faroque, Rumana, Afrin Sadia [2021], "Creative social media use for Covid-19 prevention in Bangladesh: a structural equation modeling approach", Social Network Analysis and Mining, https://doi.org/10.1007/s13278021-00744-0

4. Shahid, Shehroz, Mangrio, Ramsha Habibullah, Abbas, Munib, Ali, Zeesan, Ahmed, Masroor,"Evaluation of Knowledge and Belief on False Reports and Misinformation from Social Media in COVID-19 Pandemic: A Web Based Cross-Sectional Survey in Karachy, Pakistan". European Scientific Journal [ESJ], Vol.16, No.36, p.1-10, doi: 10.19044/esj.2020.v16n36p8

5. Gundaz, Ugur (2020), "Stayhome Hashtag:Sentiment Anlysis on Twitter During the Covid-19 Pandemic,". European Scientific Journal [ESJ], Vol.16, No.34, doi:10.19044/esj.2020.v16n34p62

6. Islam, M.S., Sarkar, T., Khan, S.H., A.H.M., Kamal, Hasan, S.M.M., Kabir, A., Yeasmin, D., Islam, M.A., Choudhury, K.I.A., Anwar, 
K.S., Chughtai, A.A., \& Seale, H. (2020); "COVID-19 Related Infomedic and its Impact on Public Health: A Global Social Media Analysis", The American Journal of Tropical Medicine and Hygiene, 103(4), 1-9, doi:10.4269/ajtmh.20-0812.

7. Tasnim, S., Hossain, M.H., and Mazumder (2020), H.; "Impact of Rumors and Misinformation on COVID-19 in Social Media", J Prev Med Pub Health, 53,171-174; doi.org/10.3961/jpmph.20.094

8. Khalifa, H., Mujeeb Absy,A.A., Badran, S., Almaamari A.Q.A., \& Nagi, M.,(2021), "COVID-19 Pandemic and Diffusion of Fake News through Social Media in the Arab World". www.arabmediasociety.com

9. Apuke, O. D., \& Omar, B. (2020). "Fake news and COVID-19: modelling the predictors of fake news sharing among social media users." Telematics and Informatics, 101475 doi.org/10.1016/j.tele.2020.101475.

10. Islam, M.A., Mondal, R.U., and Hasan, M.Z., (2009). "Performance Evaluation of WiMAX Physical Layer under Adaptive Modulation Techniques and Communication Channels", International Journal of Computer Science and Information Security, IJCSIS, Vol. 5, No. 1, pp. 111-114, USA.

11. Islam, M.A., and Islam, A.Z.M.T., (2012). "Performance of WiMAX Physical Layer with Variations in Channel Coding and Digital Modulation Under Realistic Channel Conditions", International Journal of Information Sciences and Techniques, IJIST, Vol. 2, pp. 3947, No. 4.

12. Aown, N.T., Islam, M.A., Rahman, M.Z., and Islam, A.Z.M.T., (2012). "Effect of AWGN \& Fading (Rayleigh \& Rician) channels on BER performance of a WiMAX communication System", International Journal of Computer Science and Information Security, IJCSIS, Vol. 10, No. 8, USA.

13. Halim, M.A., Islam, M.A.,, Islam, T., Homyara, H., and Zaman, M., (2012). "Performance Analysis of Cyclic Redundancy Check(CRC) encoded Fixed WiMAX Wireless Communication System under Implementation of M-ary Quadrature Amplitude Modulation(QAM) Technique", International Journal of Engineering Research and Applications (IJERA), Vol. 2, No. 5, pp. 1056-1062.

14. Islam, M.A., and Islam, A. Z. M. T., (2014). "Secure Wireless Text Message Transmission with the Implementation of RSA Cryptographic Algorithm", International Journal of Computer Networks and Communications Security, VOL. 2, NO. 5, pp:146-151, United Arab Emirates. 
15. Tai, M.P., Islam, M.A., Enam, F., and Rahman, M.A., (2016). "Secure Color Image Transmission Over WIMAX Communication System", Journal of Multidisciplinary Engineering Science and Technology (JMEST), Vol. 3 Issue 6, page 5040-5047, Berlin, Germany.

16. Roy, S.C., Ali, M.M., and Islam, M.A., (2019). "Analysis the Effect of Transmission Cost on TTL and Number of Nodes in Social Aware Routing Protocols", International Journal of Scientific \& Engineering Research, Vol-10, Issue-9. doi: 10.14299/ijser.2019.09.06

17. Islam, M.A., Das, D., Homyara, H., and Islam, A. Z. M. T., (2014). "BER Performance of CRC Coded LTE System for Various Modulation Schemes and Channel Conditions", Scientific Research Journal (Scirj), Volume II, Issue V, p:6-10.

18. Rahman, M.A., and Islam, M.A., (2020). "Comparative Study on the Impact of Mobile Communication System on Social Life", European Journal of Social Sciences Education and Research, Vol.7, Issues. 1, pp:137-148. DOI: 10.26417/ejser.v7i1.p137-148

19. Reid, K. (2009). "The rise of social networking sites." Education Journal, 119(22). search.ebscohost.com

20. Aykurt, Aylin Yildirim and Sesen, Elif [2017], "Social Media in Social Organization." European Scientific Journal [ESJ],V.13, N.20, p:1722, doi: 10.19044/esj.2017.v13n20p1.

21. Mikami, A. Y., Szwedo, D. E., Allen, J. P., Evans, M. A., \& Hare, A. L. (2010). "Adolescent Peer Relationships and Behavior Problems Predict young adults". communication on social networking websites, Developmental Psychology, 46(1), pp:46-56.

22. W. Thomas, "Cell phone health effects: busy signals think twice before you place that call". http://willthomas.net

23. Landsverk, G., (2020). "Holding Your Breath Can't Help You Selfdiagnose the Coronavirus. Here What You Should Do Instead". Business Insider Australia. Australia.

24. www.statista.com

25. www.thestatesman.com

26. www.bbc.com/news/world-51429400

27. www.tandfonline.com

28. www.ncbi.nlm.nih.gov

29. www.weforum.org

30. socialnetworking.procon.org

31. www.hrw.org/news 